\title{
Pulmonary arterial hypertension associated with systemic sclerosis
}

\author{
Stephen C Mathai ${ }^{1}$ and Paul M Hassoun ${ }^{\dagger, 1}$ \\ ${ }^{1}$ Division of Pulmonary and Critical Care Medicine, Department of Medicine, Johns Hopkins \\ School of Medicine, Baltimore, MD, USA
}

\section{Abstract}

Systemic sclerosis (SSc) is commonly complicated by pulmonary arterial hypertension (PAH), which is a leading cause of death in the SSc patient population. Owing to the fact that the risk of developing pulmonary hypertension is high, screening is important, although the optimal modality remains to be defined. Furthermore, despite recent advances in therapy for PAH, the response to these interventions in patients with PAH with SSc has been discouraging. The lack of clinical response to these therapies may merely reflect the limitations of traditionally employed PAH outcome measures in SSc-PAH patients or highlight the heterogeneity of the disease manifestations within SSc. Importantly, since extrapulmonary involvement of the GI tract and kidneys by SSc limit candidacy for lung transplantation, new therapies that target abnormal cellular proliferation in the pulmonary vasculature are currently under investigation and may be particularly relevant to SSc-PAH.

\section{Keywords}

diagnosis; pulmonary hypertension; systemic sclerosis; therapy

Pulmonary arterial hypertension (PAH), defined as a mean pulmonary artery pressure greater than $25 \mathrm{mmHg}$, pulmonary capillary wedge pressure less than $15 \mathrm{mmHg}$, and pulmonary vascular resistance greater than three Wood units, is a progressive disorder of the pulmonary vasculature that leads to right heart failure and death [1]. PAH commonly complicates systemic sclerosis (SSc) with a prevalence estimated at 8-12\% [2,3]. Importantly, PAH in SSc (SSc-PAH) significantly impacts survival, and is a leading cause of mortality in SSc [4].

Despite the high prevalence of the disease in SSc and its impact on outcomes, PAH complicating SSc remains underdiagnosed. With recent advances in our understanding of the pathogenesis of PAH in general, therapies have been developed that target the pulmonary vasculature and may improve symptoms, functional capacity and quality of life. However, patients with SSc-PAH have a strikingly divergent response to therapy and overall worse outcome than patients with idiopathic PAH (IPAH) [5-7]. While the reasons for these clinical differences remain unclear, there may be several explanations ranging from inadequacy of currently employed outcome measures for SSc-related disease to distinct differences in the right ventricle's response to increased afterload. Thus, there remains significant room for improvement in the recognition, assessment and treatment of SSc-PAH.

\footnotetext{
(C) 2011 Expert Reviews Ltd

${ }^{\dagger}$ Author for correspondence: Tel.: +1 4106146311 Fax: +1 4106147451 phassou1@jhmi.edu.
} 


\section{Epidemiology of SSc}

Systemic sclerosis is a heterogeneous disorder characterized by dysfunction of the immune system, endothelium and fibroblasts that leads to fibrosis of the skin and internal organs [8]. Vascular hyper-reactivity and obliterative micro-vascular disease are also prominent features of the disorder. Although the etiology of the disease is unknown, genetic and environmental factors are thought to contribute to host susceptibility [9]. Whereas the relative risk of developing SSc for first-degree relatives and siblings has been shown to be high, twin studies demonstrated similar concordance between monozygotic and dizygotic twin pairs, suggesting that an acquired environmental exposure is integral to disease development $[10,11]$. Several sporadic clusters of high prevalence populations have been reported, along with clusters of SSc-like syndromes implicating exposure to silica and solvents as potential environmental risk factors [12]. Geographic clusters, such as the one described in the Choctaw Indians of Oklahoma, USA, by Arnett $e t$ al., where the prevalence was estimated at 4690 per million, suggest not only a genetic predisposition, but also a potential role for environmental factors [10]. However, the relationship between exposure and risk of development of SSc has been variable and not reproducible; therefore the impact of environmental exposures upon the development of SSc remains to be defined [12].

Despite widely varying estimates of disease occurrence from 1940 to 1970, the incidence and prevalence of the disease has remained relatively stable over the past 30 years, coinciding with the introduction of a uniformly accepted classification system in 1980 [13]. Still, population-based studies suggest that SSc occurs more commonly in the USA than in other countries. A study by Mayes et al. estimates the prevalence to be approximately 242 per million in the USA whereas studies in Europe and Japan estimate the prevalence from 30 to 70 cases per million [14-16]. These observations further support a role for environmental exposure in the development of the disease.

Additional risk factors for the development of SSc have been studied. Ethnicity seems to play an important role; the Black population of the USA have a higher age-specific incidence, earlier age of disease onset, and more severe disease than the White population [17]. Studies from France have demonstrated a higher prevalence of SSc in non-Europeans than Europeans [18]. Overall, it appears that SSc occurs more commonly in Black, Asian and some Native American populations in the USA (such as the Choctaws Indians) than in individuals of European descent. Women are more likely to be affected by SSc, by a ratio of approximately of 3:1. Hormonal factors along with gender-specific environmental exposures have been proposed as potential explanations for this observation [19]. Age may also play a role as SSc is rare in childhood and very elderly individuals; the peak incidence is in the fifth decade of life $[17,20]$.

\section{Clinical features of SSc}

Clinically, SSc manifests as either limited cutaneous SSc with limited skin and other organ involvement or diffuse cutaneous SSc with extensive skin fibrosis and widespread internal organ involvement. The American College of Rheumatology classification criteria for SSc include the major criterion of skin thickening or induration proximal to the metacarpophalangeal or metatarsophalangeal joints, and three minor criteria of sclerodactyly, digital pitting, or loss of finger pad substance, and bibasilar pulmonary fibrosis not attributable to primary lung disease [21,22]. One major and at least two minor criteria are required to establish the diagnosis. SSc in either the limited or diffuse form results in a reduced life expectancy with an overall median survival of approximately 12 years from diagnosis $[13,14]$. Multiple organ systems can be affected in SSc, including the gastrointestinal, cardiac, renal, integument and pulmonary systems. 
Pulmonary involvement in SSc is varied, but occurs frequently in both the limited and diffuse forms of the disease. While interstitial lung disease (ILD) and PAH are the most common manifestations of pulmonary disease in SSc, other forms of pulmonary involvement can occur. Gastrointestinal involvement of the upper digestive tract often leads to gastroesophageal reflux disease and aspiration of gastric contents. Chronic aspiration may also contribute to the development of ILD, although further research is needed to establish a causal relationship $[23,24]$. Patients with SSc may also have a higher risk of lung carcinoma, particularly bronchoalveolar carcinoma, although a more recent population-based study did not find a higher risk of lung cancer in SSc [25,26]. Other pulmonary complications that can present with SSc include restrictive lung disease related to respiratory muscle weakness [27] and pleural effusion, although this is rare [28]. An obstructive ventilatory defect has been observed in nonsmoker patients with scleroderma [29]. Spontaneous pneumothorax has also been reported, often in association with subpleural blebs in the context of ILD [30].

Interstitial lung disease is the most common pulmonary complication in SSc, with up to $40 \%$ of patients demonstrating restrictive patterns on pulmonary function testing and more than $90 \%$ with ILD at autopsy [31]. Although ILD is more commonly associated with the diffuse form of SSc, it also occurs in patients with limited disease and does not correlate with the extent of skin involvement [32,33]. ILD may develop earlier in the course of the disease in the US Black population, patients with higher skin scores and serum creatinine phosphokinase levels, hypo thyroidism and cardiac involvement [34]. Overall, patients with significant ILD have a much poorer prognosis than patients without significant ILD with 9year survival at 32 versus $72 \%$, respectively [35]. ILD can also be complicated by the development of pulmonary hypertension $(\mathrm{PH})$, which is discussed in detail below.

\section{Epidemiology of PAH in SSc}

As discussed, PAH is defined as a mean pulmonary artery pressure greater than $25 \mathrm{mmHg}$, with a pulmonary capillary wedge pressure of less than $15 \mathrm{mmHg}$, and a pulmonary vascular resistance greater than three Wood units [1]. PAH commonly complicates SSc, but establishing the incidence and prevalence of PAH in SSc has been challenging, similar to estimating the incidence and prevalence of SSc in general. Based upon the definition of PH and the method employed to diagnose $\mathrm{PH}$ (i.e., echocardiography or right heart catheterization [RHC]), the estimates of prevalence have ranged from 5 to $60 \%[13,15,36-$ 39]. Based on strict hemodynamic criteria for the definition of PAH and with a conservative estimate of PAH prevalence of $10 \%$ in SSc, the prevalence of SSc-PAH in the USA may be as high as 24 cases per million, nearly fourfold higher than the prevalence of IPAH [38]. Despite this, recent data from a US-based registry study suggests that IPAH is at least twofold more common than SSc-PAH, perhaps reflecting under-recognition of PAH in the SSc population [40].

\section{Autoimmunity, autoantibodies \& PAH pathogenesis}

The histological features of the arteriolar vasculopathy in SSc-PAH share similarity with those of IPAH including intimal hyperplasia, medial hypertrophy and adventitial fibrosis. Occlusion of small arteries with concentric obliterative endothelial cell lesions and angioproliferative plexiform lesions have also been described in in SSc-PAH; however, there are fewer plexiform lesions, increased intimal fibrosis and more heterogeneity when compared with the lesions of IPAH [41]. Two recent histological studies have shown that the presence of pulmonary veno-occlusive disease, characterized by fibrous remodeling of post-capillary venules and preseptal veins, may be more common in patients with SSc-PAH compared with IPAH [41,42]; however, this needs to be confirmed in larger studies. 
Autoimmunity appears to play a central role in pulmonary vascular remodeling, which is the hallmark of PAH. Characteristic vascular changes occur early after the onset of SSc [43,44]. These include endothelial cell apoptosis and activation with expression of cell adhesion molecules, inflammatory cell recruitment, procoagulant state, and intimal proliferation and adventitial fibrosis leading to vessel obliteration $[45,46]$. Several studies in SSc patients have demonstrated increased circulating factors that are associated with each of these pathways. For instance, increased levels of soluble VCAM-1 have been found in SSc patients, consistent with endothelial injury [47]. Similarly, investigators have shown increased levels of circulating VEGF and angiostatic factors in patients with SSc, suggesting abnormal regulation of angiogenesis [48-51]. Increased VEGF, a glycoprotein with potent angiogenic and vascular permeabilityenhancing properties, may be a consequence of increased angiogenesis or profound disturbances in signaling in SSc. Dysregulated angiogenesis may play an important role in the development of SSc-PAH as shown in genomic studies [52]. Whether driven by the inflammatory process or intrinsically related to the disease state, abnormal angiogenesis appears to be a predominant feature of the disorder in SSc and should be the focus of future studies.

Autoantibodies are often associated with the development of certain phenotypes in SSc and with the subsequent development of PAH. For instance, antifibrillarin antibodies (anti-U3RNP) are commonly found in patients with SSc-PAH [53]. However, the relationship of these autoantibodies to pathogenesis remains to be fully elucidated. Progress in this area is limited by current techniques for identification of autoantibodies that utilize transformed epithelial cell lines that fail to detect phenotype-specific autoantigens uniquely expressed in target tissues, such as the endothelial cell [54]. Despite this, there is a growing body of evidence supporting a pathogenic role of certain autoantibodies in SSc and potentially, SScPAH. IgG antibodies directed against endothelial cells and obtained from patients with IPAH and SSc-PAH display distinct reactivity profiles against antigens form the micro- and macro-vascular beds [55]. Antibodies to fibrin-bound tissue plasminogen activator in patients with limited SSc and anti-topoisomerase II-a antibodies, particularly in association with HLA-B35 antigen, have been reported in SSc-PAH [56]. Anti-endothelial cell antibodies, which have been shown to correlate clinically with the presence of digital infarcts, may play a role in the pathogenesis of PAH; and aECA can activate endothelial cells and induce the expression of adhesion molecules and trigger apoptosis [57,58].

Fibroblasts are essential components of the pulmonary vascular wall remodeling in PAH and can be found in the remodeled neointimal layer in both SSc-PAH and IPAH [59]. The detection of antifibroblast antibodies in the serum of SSc and IPAH patients has significant pathogenic importance because these antibodies can activate fibroblasts and induce collagen synthesis, thus potentially contributing directly to the remodeling process. Antibodies from sera of patients with SSc can induce a pro-adhesive and proinflammatory response in normal fibroblasts [60]. IgG antifibroblast antigens recognized by serum IgG from IPAH and SSc$\mathrm{PAH}$ patients that have been identified include proteins involved in regulation of cytoskeletal function, cell contraction, cell and oxidative stress, and other key cellular pathways [61]. It is thought that these fibroblast autoantibodies mediate the release of cytokines and growth factors, which in turn contribute to the pathogenesis of vascular remodeling in PAH.

Very recently, Riemekasten et al. demonstrated that functional immunity directed at angiotensin II type 1 receptor and endothelin-1 type A receptor were commonly found in patients with SSc, particularly in patients with diffuse SSc [62]. In addition, these antibodies were associated with more severe disease manifestations and late complications, including pulmonary hypertension, lung fibrosis and digital ulcers. Of particular interest is that both angiotensin II type 1 receptor and endothelin- 1 type A anti bodies stimulate phosphorylation 
of ERK1/2 and increase TGF- $\beta$ transcripts in cultured microvascular endothelial cells, effects which could be blocked with specific receptor antagonists. Thus, the authors speculate that these antibodies could contribute to disease pathogenesis and may serve as potential biomarkers. These studies also highlight the potential benefit of specifically targeting the rennin-angiotensin and endothelin systems in SSc.

In aggregate, these data suggest a prominent role of inflammation and autoimmunity in the pathogenesis of PAH, particularly in SSc, although this field of research needs to be further investigated in terms of direct causality (with disease manifestation such as PAH), potential value for biomarker use and possibility of targeted therapy. With regards to the latter, it is important to note that, in contrast to PAH associated with other autoimmune diseases, such as systemic lupus erythematosus and mixed connective tissue disease, the lack of clinical response to immunosuppressive agents in SSc-PAH clearly highlights our limited understanding of these factors in the development and progression of pulmonary vascular disease in SSc [63,64].

\section{Genetic factors in scleroderma-related PAH}

While recent research in the role of genetics in PAH has identified relevant polymorphisms that contribute to the development of the disease, there is a paucity of data regarding the genetic basis for the development of PAH in SSc. For example, polymorphisms in the bone morphogenic protein receptor-II gene (BMPRII) are present in $80 \%$ of familial PAH and approximately $20 \%$ of sporadic cases of PAH [65]. Further, polymorphisms in other genes related to TGF- $\beta$, such as activin-receptor-like kinase-1, which encodes for the TGF- $\beta$ receptor, have been found in patients with $\mathrm{PAH}$ and hereditary hemorrhagic telangiectasia [66]. Further, the presence of these polymorphisms may affect outcomes. A recent study by Girerd et al. found the presence of an activin-receptor-like kinase-1 polymorphism to be associated with a poorer outcome when compared with BMPRII mutation carriers and noncarriers [67].

While these genetic polymorphisms have been demonstrated to be associated with familial and idiopathic forms of PAH, to date, no studies have identified the presence of BMPRII mutations in SSc-PAH $[68,69]$. Polymorphisms in a gene encoding endoglin, a homodimeric membrane glycoprotein primarily present on human vascular endothelium, which is part of the TGF- $\beta$ receptor complex, have recently been shown to be associated with SSc-PAH [70]. Wipff $e t$ al. studied a six-base intron insertion in the endoglin gene and found significantly different frequencies of this polymorphism between SSc patients with and without PAH and between SSc-PAH patients and controls. However, this finding has yet to be validated in other cohorts. Further, the functional significance of endoglin in SSc-PAH has yet to be described. Other genetic studies have identified associations with polymorphisms in inflammatory genes, such as IL-1 $\beta$, IL-2, and TNF- $\alpha$-induced protein 3, and SSc subtypes $[71,72]$. However, the studies were either underpowered to demonstrate a convincing relationship with SSc-PAH or have yet to be replicated in other cohorts.

\section{Clinical features}

\section{Definition of PAH}

As discussed previously, the diagnosis of SSc-PAH is based on a hemodynamic profile obtained by RHC and exclusion of other entities such as thromboembolic disease, left ventricular dysfunction, valvular disease and significant lung parenchymal disease [1]. It is important to emphasize that despite advances in noninvasive imaging techniques, a RHC is required to establish the diagnosis. Exclusion of significant ILD is especially important for the proper classification of SSc patients with suspected PH given the high prevalence of ILD 
in SSc. However, no standard definition of significant ILD exists in the literature. Most clinical studies of cohorts of SSc-PAH patients $[3,73,74]$ have defined significant ILD as a total lung capacity of $<60 \%$ of predicted or a total lung capacity between 60 and $70 \%$ of predicted combined with moderate-to-severe fibrosis (grade 3-4) evident on high-resolution CT scan using the criteria proposed by MacDonald et al. [75]. We and others have shown poorer survival for SSc patients with PH related to significant ILD compared with patients with PAH, and currently available vasodilator therapy is only US FDA-approved for PAH $[76,77]$.

\section{Risk factors}

As discussed in the section on epidemiology of SSc-PAH, patients with SSc are at high risk of developing PAH. Certain clinical characteristics have been associated with the development of PAH in this population. First, patients with the limited form of the disease are more likely to develop PAH, although approximately $13-25 \%$ of patients with PAH have the diffuse form of SSc [2,78]. Typically, SSc-PAH will develop after 10-15 years of evolution of the disease in the limited form [79]. Second, patients who develop SSc later in life are at higher risk of developing PAH [80]. Third, pulmonary function abnormalities, such as an isolated reduction of diffusing capacity for carbon monoxide $\left(\mathrm{DL}_{\mathrm{CO}}\right)$, a ratio of percentage forced vital capacity $(\mathrm{FVC} \%)$ to percentage $\mathrm{DL}_{\mathrm{CO}}$ ratio greater than 1.6, or a combined decrease in $\mathrm{DL}_{\mathrm{CO}}$ /alveolar volume $\left(\mathrm{V}_{\mathrm{A}}\right)$ with elevated serum $\mathrm{N}$-terminal probrain natriuretic peptide (NT-proBNP) levels have been associated with the development of PAH in cohorts of patients with SSc [79,81,82]. Additionally, certain autoantibody profiles have been associated with increased risk of PAH, particularly in limited SSc. Approximately $20 \%$ of patients with anticentromere antibodies will develop SSc-PAH, whereas over $30 \%$ of SSc patients with anti-Th/To antibodies can develop PAH [83]. However, since anti-Th/ To patients will not be identified by ELISA antinuclear antibody testing methods (leading to a negative antinuclear antibody), identification of this high-risk subset is challenging. Patients with anti-U1-RNP or anti-U3-RNP (which tends to be associated with diffuse SSc) antibodies also have a higher risk of developing PAH.

\section{Clinical features of SSc-PAH}

Typically, patients with SSc-PAH are predominantly women, have limited SSc, and tend to be older. Clinical symptoms of PAH tend to be nonspecific, including dyspnea and functional limitations that may be related in part to concomitant musculoskeletal disease. In addition, other organ systems are commonly affected in SSc. Renal disease is prevalent, and may be more common than in IPAH [84]. Direct cardiac involvement can also occur, affecting the myocardium, pericardium and/or small intramyocardial vessels by vascular, fibrotic and inflammatory changes [85]. These processes may lead to left ventricular dysfunction; we have found a higher prevalence of nonsystolic left ventricle dysfunction as assessed by echocardiography in SSc-PAH compared with IPAH [6]. Furthermore, SScPAH patients more commonly present with pericardial effusion than IPAH, although it remains unknown whether the effusions are related to progressive right ventricle (RV) dysfunction or to the underlying autoimmune process. Hormonal and metabolic dysfunction is also common, as evidenced by signs of neurohormonal activation. NT-proBNP, a neuro peptide released in response to ventricular stretch, is frequently elevated in SSc-PAH and appears to be significantly higher than in IPAH patients despite similar hemodynamic perturbations [86]. Similarly, hyponatremia, a marker of neurohormonal activation, is common in SSc-PAH and portends a poor prognosis [87]. Whether these neurohormonal abnormalities are related to the underlying SSc or to progressive pulmonary vascular disease remains to be determined. 
When compared with IPAH, SSc-PAH patients demonstrate seemingly less severe hemodynamic impairment [6]. However, traditional hemodynamic measures of disease severity, such as cardiac index (CI) and right atrial pressure (RAP), which have previously been demonstrated to strongly predict survival in IPAH, are inconsistently associated with outcomes in SSc-PAH $[6,77,78]$. The ability of the RV to adapt to the increased cardiac load attendant with PAH is the main determinant of outcome in PAH [88]. Recent studies utilizing pressure-volume relationships have demonstrated differential responses to cardiac loads between IPAH and SSc-PAH, with decreased mean ventricular pressure at any given afterload in SSc-PAH [89]. Our group has demonstrated that measures of RV afterload, both proximal and distal vascular resistance (pulmonary arterial capacitance as estimated by stroke volume divided by pulmonary artery pulse pressure and pulmonary vascular resistance, respectively) independently predict survival in SSc-PAH [78]. Furthermore, stroke volume index, a measure of RV function, was also strongly predictive of outcome in this cohort; neither CI nor RAP independently predicted survival. Taken together, these data suggest that the RV response to cardiac load differs between IPAH and SSc-PAH and may be contributing to poorer outcomes in SSc-PAH.

\section{Screening \& assessment}

A recently published consensus statement from the American College of Cardiology, American College of Chest Physicians, American Thoracic Society, and Pulmonary Hypertension Association recommends yearly echocardiography for patients with SSc to screen for PH [1]. While this practice has been employed at many specialized centers, variations in its implementation exist, both between community-based practices and referral centers, and between specialties (i.e., rheumatologists and pulmonologists) [90-92]. In addition, pulmonary function test abnormalities, such as decline in $\mathrm{DL}_{\mathrm{CO}}$, alone or in combination with elevation in serum NT-proBNP, or a $\mathrm{FVC} \%-\mathrm{DL}_{\mathrm{CO}} \%$ ratio greater than 1.6, may identify SSc patients with $\mathrm{PAH}$, but may not be routinely performed by clinicians $[79,82]$. A proposed algorithm for detection of PAH in patients with SSc, utilizing a combination of symptoms and objective findings, is presented in Figure 1. Given that a population at risk for PAH such as SSc theoretically allows the establishment of measures for early detection, this algorithmic approach may be helpful as evidenced by a large French registry [3]. In this registry, SSc patients underwent RHC if there was echocardiographic evidence of $\mathrm{PH}$, defined by a tricuspid regurgitant jet velocity greater than $3 \mathrm{~m} / \mathrm{sec}$, or a tricuspid regurgitation velocity between 2.5 and $3.0 \mathrm{~m} / \mathrm{sec}$ if accompanied by unexplained dyspnea. Investigators were able to detect incident cases of SSc-PAH with less severe disease (by hemodynamic measures) compared with patients with known disease. Thus, unexplained dyspnea should prompt an evaluation for PAH in these patients, particularly if other risk factors, such as low $\mathrm{DL}_{\mathrm{CO}}, \mathrm{FVC}: \mathrm{DL}_{\mathrm{CO}}>1.6$, or low $\mathrm{DL}_{\mathrm{CO}} / \mathrm{V}_{\mathrm{A}}$ with high NTproBNP, are present.

In addition to the challenges in diagnosing PAH in patients with SSc, the outcome measures currently utilized in the assessment of PAH may not be adequate or appropriate in SSc-PAH. For instance, as noted previously, right atrial pressure and CI are not predictive of survival in SSc-PAH despite being strongly associated with outcome in IPAH. Similarly, the most commonly used outcome measure in clinical trials, the 6-min walk test (6MWT), may not be an appropriate outcome measure in SSc-PAH. While this test has been validated as a measure of cardiopulmonary exercise capacity in patients with IPAH, the 6MWT has not been validated in this manner in SSc-PAH $[93,94]$. Furthermore, the minimally important difference (MID) for the 6MWT, defined as the smallest difference in an outcome measure that identifies a clinically meaningful change in outcome as opposed to a solely statistically significant change in outcome, has yet to be defined in SSc-PAH. While the MID has been recently described in a large cohort of patients with PAH from the Sildenafil Use in 
Pulmonary Arterial Hypertension (SUPER) Study, the small number of SSc-PAH patients included in the study prevent the determination of the MID for this subset $[95,96]$. Further limitations to the utility of the 6MWT in SSc-PAH include the impact of musculoskeletal disease and subclinical ILD upon distance achieved [94,97]. These factors affecting the total distance achieved have important implications regarding prognosis and assessment of response to therapy since prior studies in IPAH patients have identified clinically important 6MWT distance thresholds both at baseline and after therapy $[93,98,99]$.

Other noninvasive measures have recently been studied as potential outcome measures for PAH and SSc-PAH in particular [100]. Serum markers, such as uric acid, may be useful for prognosis in IPAH, but neither the relevance in SSc-PAH or the responsiveness to PAHspecific therapy have been described [101]. Serum NT-proBNP has been demonstrated to correlate with disease severity and predict survival in IPAH [102]. Recent studies in SScPAH have suggested the utility of NT-proBNP to predict the development of PAH in SSc and to predict survival in SSc-PAH [82,103]. Furthermore, our experience suggests that NTproBNP levels significantly differ between IPAH and SSc-PAH despite similar hemodynamic characteristics and that NT-proBNP predicts survival only in SSc-PAH, emphasizing the potential role of NT-proBNP in the assessment of PAH in SSc patients [86]. Echocardiographic measures, such as the tricuspid annular plane systolic excursion, may offer an easily obtained, reproducible measure of PAH severity and RV function that may be useful in both IPAH and SSc-PAH [104]. Cardiac MRI is being utilized with increasing frequency in the assessment of PAH in general and SSc-PAH in particular. Besides parameters of RV size and function, we and others are focusing on assessment of the interaction between the pulmonary vasculature and the right ventricle in SSc-PAH compared with IPAH in hopes of elucidating novel markers of disease.

\section{Treatment of PAH}

With improved understanding of the pathogenesis of PAH, novel therapies targeting select pathways have been developed, with a focus on the chronically impaired endothelial function, affecting vascular tone and remodeling [105-107]. More recently, the observation of aberrant proliferation of endothelial and smooth muscle cells in PAH, with increased expression of secreted growth factors, has led some investigators to liken PAH to a neoplastic process [108]. As such, antineoplastic agents have recently been employed in therapy of PAH.

While similarities in certain aspects of the putative pathogenesis of PAH exist in SSc-PAH, clinical differences in response to therapy and outcomes suggest that distinct pathobiologic mechanisms may be involved in SSc-PAH. We will first review more traditional therapies for PAH and their relevance in SSc-PAH, then discuss novel therapies for SSc-PAH. Figure 2 depicts our treatment algorithm for SSc-PAH.

\section{General measures}

Although limited data exist for either IPAH or SSc-PAH, consensus guidelines recommend the use of:

- Supplemental oxygen in patients who are hypoxic at rest or with exercise (oxygen saturation $<90 \%$ );

- Diuretics for the management of volume overload and in overt right heart failure;

- Digoxin for management of refractory right heart failure complicated by atrial arrhythmias. 


\section{Calcium channel blockers}

Although commonly used in patients with SSc for treatment of Raynaud's phenomenon, there is little role for calcium channel blockers in the treatment of SSc-PAH. Vasoreactivity is defined as a decrease in mean pulmonary arterial pressure by at least $20 \%$ and to less than $40 \mathrm{mmHg}$ without a decline in CI or an increase in pulmonary capillary wedge pressure in response to a short-acting vasodilator such as inhaled nitric oxide. It is present in only a minority of patients with IPAH $(\sim 12 \%)$ and in approximately $1 \%$ of SSc-PAH patients [109]. While presence of vasoreactivity suggests potential response to high-dose calcium channel blocker therapy and, in general, portends a better prognosis, approximately half of the initial responders will have diminution of the vasoreactivity over time. Thus, high-dose calcium channel blocker therapy for treatment of PAH is rarely indicated in SSc-PAH.

\section{Anticoagulation}

While pulmonary thromboembolic arterial disease and thrombosis in situ has been found in pathologic studies of patients with IPAH, there are few reports in the literature of similar findings in SSc-PAH [110]. Similarly, there are no data on the role of anticoagulation in the treatment of SSc-PAH. Several retrospective studies and one nonrandomized prospective study have suggested improved outcomes in IPAH, while two retrospective studies suggested no clinical benefit [111]. Still, despite a lack of randomized controlled trials, consensus guidelines recommend anti coagulation for all IPAH patients and for patients with PAH related to connective tissue diseases who have 'advanced' disease [1]. While we encourage all of our SSc-PAH patients to begin oral anti coagulation, our experience in over 100 SSc-PAH patients suggests that less than 50\% remain on long-term anticoagulation therapy. Most often, patients develop occult lower gastrointestinal bleeding that necessitates cessation of anticoagulation.

\section{Prostaglandins}

Prostacyclin (epoprostenol) has proven effective in the management of PAH, demonstrating improvements in exercise capacity, cardiopulmonary hemodynamics, functional classification (New York Heart Association classification) and symptoms in patients with IPAH $[112,113]$. In fact, epoprostenol remains the only PAH-specific therapy to demonstrate a survival benefit in a randomized clinical trial [112]. In SSc-PAH, continuous intravenous epoprostenol improved exercise capacity and hemodynamics compared with conventional therapy, but failed to improve survival [114]. Similar, albeit modest, responses to the prostacyclin analogue treprostinil, delivered through continuous subcutaneous infusion, were noted between IPAH and PAH related to connective tissue diseases [73,115]. However, while functional capacity, exercise capacity, and hemodynamics improved in both IPAH and PAH associated with connective tissue disease (PAH-CTD), only half of the PAH-CTD group had SSc. Furthermore, the efficacy of treprostinil appears to be doserelated and the subcutaneous route of administration can be limited by infusion site pain. Recently, the intravenous form of treprostinil has been approved by regulatory agencies for the treatment of PAH, including SSc-PAH. Although required maintenance doses are usually twice as high when compared with epoprostenol (affecting the cost of administration), the safety profile and drug stability offers potentially significant advantages in SSc-PAH [116]. For example, the lack of requirement for ice packing may be particularly important for SSc patients who suffer from Raynaud's phenomenon. Still, despite the potential efficacy of prostacyclin agents, the need for continuous infusion, meticulous catheter care and daily preparation of the medication can be challenging in patients whose manual dexterity may be impaired by significant Raynaud's phenomenon, sclerodactyly and digital ulcerations. At our center, many SSc-PAH patients are unable to receive parenteral therapy as a result of these physical limitations. 
Although inhaled prostacyclin analogues have been developed for the treatment of PAH, no studies or specific subgroup analyses on efficacy of inhaled iloprost in SSc-PAH have been reported. The utility of inhaled iloprost is limited by the frequency with which the medication must be dosed; many patients are unable or unwilling to take the medication sixto nine-times daily as prescribed. Inhaled treprostinil is currently available and requires less frequent dosing (four- to six-times daily). While demonstrating efficacy as add-on therapy with oral agents in a mixed cohort of PAH patients (including 40 with collagen vascular disease), subgroup analyses have not been reported [117]. However, these medications may be a useful adjunct therapy in patients who are physically unable to maintain parenteral prostacyclin therapy.

\section{Endothelin receptor antagonists}

Bosentan, the first approved oral therapy for PAH, has been shown to improve New York Heart Association functional class, 6-min walking distance (6MWD), time to clinical worsening and hemodynamics in a short-term trial of patients with PAH [118]. In a subgroup ana lysis of patients with SSc-PAH included in this initial study, there was a nonsignificant trend towards improvement in 6MWD in patients treated with bosentan compared with placebo. A 48-week, open-label study of patients with various forms of CTD, the majority of whom had SSc, demonstrated functional improvements in over $25 \%$ of these patients, while the 1-year survival was 92\% [119]. However, no 6MWTs were reported and quality of life, as assessed by the Short Form-36 and Health Assessment Questionnaire modified for SSc, did not improve. Our experience suggests that long-term outcome of SSc-PAH patients receiving bosentan as initial therapy is inferior compared with IPAH patients, with no improvement in functional class and poorer survival [120]. Still, guidelines from the European League against Rheumatism recommend bosentan as initial therapy for SSc-PAH based upon the quantity and quality of available data [121].

In an effort to target the vasoconstrictive effects of endothelin while preserving its vasodilatory action, selective endothelin-A receptor antagonists have been developed. Sitaxsentan, which had been approved in Europe for treatment of PAH, demonstrated exercise capacity, quality of life and hemodynamics in a post-hoc ana lysis of a randomized controlled trial that included 42 patients with PAH-CTD [74]. However, recently, this drug was removed from the market owing to significant hepatotoxicity and death. A large placebo-controlled, randomized trial of ambrisentan, the only currently FDA-approved selective endothelin receptor antagonist, improved 6MWD in PAH patients at week 12 of treatment; however, the effect was larger in patients with IPAH compared with patients with PAH-CTD (range: 50-60 vs 15-23 m, respectively) [122]. No other outcome measures (time to clinical worsening, change in functional class, quality of life, change in brain natriuretic peptide level or safety) were reported by PAH type. Furthermore, the proportion of CTD patients with SSc was not reported. Ambrisentan is generally well tolerated although peripheral edema (in up to $20 \%$ of patients) and congestive heart failure have been reported.

\section{Phosphodiesterase inhibitors}

Sildenafil, a phosphodiesterase type 5 inhibitor that reduces the catabolism of cGMP, leading to enhanced effects of nitric oxide, has been widely employed in the treatment of PAH. A large clinical trial demonstrated improvement in 6MWD in subjects with various forms of PAH, including CTD-related disease [96]. A post-hoc ana lysis of the PAH-CTD subjects in the larger study found improvements in $6 \mathrm{MWD}$, functional class and hemo dynamics after 12 weeks of therapy with $20 \mathrm{mg}$ three-times daily. No further improvements were noted in subjects who received either $40 \mathrm{mg}$ three-times-daily or $80 \mathrm{mg}$ three-timesdaily doses. Importantly, less than 50\% of the CTD patients in this study had SSc, thereby 
limiting the generalizability to SSc-PAH. Still, given the favorable safety profile, sildenafil is an attractive agent for initial therapy in SSc-PAH.

The results of a large, randomized study of tadalafil, a once-daily phosphodiesterase inhibitor, have been recently reported [123]. The treatment effect upon 6MWD, time to clinical worsening and quality of life was significant in subjects who received $40 \mathrm{mg}$ daily. Statistically significant improvements in 6MWD were noted in the PAH-CTD group, although the proportion of patients with SSc was not reported. Importantly, over half of the participants were on therapy with bosentan $125 \mathrm{mg}$ twice daily at enrollment, which may have impacted the magnitude of response to additional therapy with tadalafil. Thus, tadalafil may be a useful alternative to sildenafil in the treatment of SSc-PAH given its safety profile and ease of administration.

Regardless of the oral therapy selected as initial therapy, the effect upon exercise capacity may not be significant. As demonstrated in a systematic review of all randomized controlled trials evaluating the efficacy of bosentan, sitaxsentan and sildenafil, the effect size, defined as the ratio of the treatment effect (mean differences in 6MWD between treatment and placebo groups) to the pooled standard deviation of the differences, was small to moderate at best and not statistically significant for any drug studied [124]. While this study highlights the limited response in 6MWD to oral therapies in SSc-PAH, it also emphasizes the need for appropriate outcome measures in SSc-PAH as discussed previously.

\section{Combination therapy}

Given the possible synergistic effects of the available PAH therapies that target separate pathways involved in the pathogenesis of the disease, combination therapy has become common practice in pulmonary hypertension centers. Several multicenter trials are now exploring the efficacy of various combinations of oral drugs, oral and inhaled drugs, and oral and intravenous drugs. The Pulmonary Arterial Hypertension Combination Study of Epoprostenol and Sildenafil (PACES) trial demonstrated that adding sildenafil at $80 \mathrm{mg}$ three-times daily to intravenous epoprostenol improved exercise capacity, time to clinical worsening, quality of life and hemodynamics in patients with PAH [125]. However, while no subgroup analyses were reported, the improvement noted was mainly in IPAH subjects and in those whose exercise capacity was better at baseline. Furthermore, only $11 \%$ of the cohort had SSc-PAH. Therefore, it remains to be seen if addition of sildenafil to epoprostenol is efficacious in SSc-PAH.

As mentioned previously, a recent study of inhaled treprostinil as add-on therapy for PAH has demonstrated improvements in functional capacity and quality of life in a mixed cohort of PAH [117]. While over 30\% of the study participants were designated as having collagen vascular disease, the proportion of patients with SSc was not reported. Furthermore, to date, no subgroup analyses have been published.

We have found poorer response to a combination of oral therapies in SSc-PAH compared with IPAH [126]. While the addition of sildenafil to bosentan monotherapy improved 6MWD and functional class in IPAH subjects, SSc-PAH subjects did not experience significant improvement. However, clinical deterioration may have been slowed in these patients. Importantly, there were significantly more side effects in SSc-PAH subjects compared with IPAH, including hepatotoxicity. Clinically important interactions between sildenafil and bosentan, including decreasing serum concentrations of sildenafil and increasing serum levels of bosentan, can occur when coadministered [127]. Whether these interactions are the same in SSc-PAH remains unknown; however, underlying gastrointestinal disorders such as esophageal dysmotility, gastroparesis, small bowel 
malabsorption and pancreatic insufficiency may interfere with drug absorption and metabolism.

\section{Novel therapies}

Recent discoveries that highlight the aberrant proliferation of endothelial and smooth muscle cells in PAH have prompted the study of antineoplastic drugs initially in experimental models, and now in clinical trials. Two strategies are currently under investigation in randomized controlled trials: disruption of the PDGF and the VEGF pathways. STI-571/ imatinib (Gleevec $® / G l i v e c \circledR)$, which was originally developed to inhibit the Bcr-Abl kinase in the treatment of chronic myelogenous leukemia, is a dual PDGF and VEGF inhibitor that is currently under investigation for the treatment of PAH. Several case reports have suggested its utility, including one in a patient with SSc-PAH and in a patient with pulmonary veno-occlusive disease [128-132]. Since pulmonary veno-occlusive disease-like changes in the pulmonary veins and venules may be common in SSc-PAH and a potential reason for poorer response to $\mathrm{PAH}$-specific therapy, imatinib offers a potentially attractive alternative therapy [42]. A Phase II study to evaluate the safety, tolerability and efficacy of imatinib in PAH has been completed. While the study failed to demonstrate improvement in 6MWD in an intention-to-treat ana lysis, there were statistically significant improvements in hemodynamic measurements [133]. Post-hoc analyses suggested improvements in patients with more significant hemodynamic impairment. As such, a trial investigating the efficacy of this agent in patients with severe disease is currently ongoing. Given the potential role of autoimmunity in the pathogenesis of SSc-PAH, therapies targeting B cells are also being studied. Currently, a randomized clinical trial of rituximab, an anti-CD20 therapy that depletes B-cell lineages, is specifically and exclusively enrolling SSc-PAH patients who are already on concomitant $\mathrm{PAH}$-specific therapy to assess hemodynamic response.

Recently, the transcription factor Fos-related antigen-2 (Fra-2), a member of the activator protein 1 (AP-1) family implicated in TGF- $\beta$ and PDGF signaling has been found to be highly expressed in patients with SSc [134]. Since transgenic overexpression of Fra-2 causes fibrosis and vascular disease (e.g., severe peripheral microangiopathy) [135], this factor may serve as a potential therapeutic target.

\section{Lung transplantation}

Despite the advances in medical therapy for $\mathrm{PAH}$, lung transplantation remains the final therapeutic option. Although CTD is not an absolute contraindication to lung transplantation, SSc patients tend to have multiorgan disease that increases peri- and postoperative risk. In particular, esophageal dysmotility, common in SSc, may increase the risk of aspiration and post- transplant dysfunction. Clinical and subclinical renal disease may also increase the likelihood of complications related to the prolonged use of potentially nephrotoxic immunosuppressive agents. For these reasons, SSc-PAH patients are often denied lung transplantation. However, our experience shows that with proper screening, patients with SSc have similar rates of survival after lung transplantation compared with patients with pulmonary fibrosis or IPAH [136].

\section{Outcomes}

Survival in SSc-PAH remains poor, despite the implementation of PAH-specific therapy that, in general, has improved quality of life and functional capacity in patients with IPAH. When compared with IPAH, SSc-PAH patients have at least a threefold increased risk of death $[5,6]$. The reasons for a diminished response to therapy and poorer survival remain unclear, but are probably related to the underlying effect of SSc on the heart, vasculature and other organs such as the kidney and GI tract. A better understanding of the complex 
pathogenic alterations in the way the RV adapts to increased afterload in SSc-PAH is necessary to improve targeted therapy. Whether specific anti-inflammatory agents or drugs targeting tyrosine kinase activity hold any promise of enhanced response is unknown at this time.

\section{Conclusion}

Pulmonary arterial hypertension commonly complicates SSc and is probably underrecognized. Unfortunately, despite advances in therapy for PAH in general, patients with PAH related to SSc have a poorer response to therapy and poorer survival. Similarly, currently employed markers of disease severity and outcome measures are inadequate. Therefore, there is an urgent need to identify biomarkers of disease severity and outcome measures relevant to SSc-PAH. Furthermore, increased understanding of the pathogenesis of $\mathrm{PAH}$ in SSc is imperative to develop therapies that target pathways specific to this disease.

\section{Expert commentary}

Scleroderma-related PAH, a syndrome with unacceptably high morbidity and mortality, remains difficult to treat with current medical therapy. The reasons for a generally poorer outcome compared with other forms of PAH may be related to the fact that scleroderma is a multi system disease impacting, in addition to the lung parenchyma and pulmonary vessels, the heart, kidneys and GI tract. Thus, current use of end points to judge the potential efficacy of modern treatment appears inadequate compared with other forms of PAH. A better understanding of the patho physiology of the pulmonary vascular remodeling in this syndrome, and its impact on the heart and other vital organs (such as the heart and kidney) will likely provide clues to more effective therapy and better outcome.

\section{Five-year view}

Improved survival for patients with SSc-PAH will result from a better understanding of the genetics and the factors (such as inflammatory processes) involved in the pathogenesis of this disease. This should lead to targeted therapy which may include anti-inflammatory and antiproliferative drugs in the future.

\section{Acknowledgments}

Financial \& competing interests disclosure

Supported by the NIH/National Heart, Lung and Blood Institute via grant numbers K23 HL092287 (Stephen C Mathai) and P50 HL084946 (Paul M Hassoun). The authors have no other relevant affiliations or financial involvement with any organization or entity with a financial interest in or financial conflict with the subject matter or materials discussed in the manuscript apart from those disclosed.

No writing assistance was utilized in the production of this manuscript.

\section{References}

1. McLaughlin VV, Archer SL, Badesch DB, et al. ACCF/AHA 2009 expert consensus document on pulmonary hypertension a report of the American College of Cardiology Foundation Task Force on Expert Consensus Documents and the American Heart Association developed in collaboration with the American College of Chest Physicians; American Thoracic Society, Inc.; and the Pulmonary Hypertension Association. J. Am. Coll. Cardiol. 2009; 53(17):1573-1619. [PubMed: 19389575]

2. Mukerjee D, St George D, Coleiro B, et al. Prevalence and outcome in systemic sclerosis associated pulmonary arterial hypertension: application of a registry approach. Ann. Rheum. Dis. 2003; 62(11):1088-1093. [PubMed: 14583573] 
3. Hachulla E, Gressin V, Guillevin L, et al. Early detection of pulmonary arterial hypertension in systemic sclerosis: a French nationwide prospective multicenter study. Arthritis Rheum. 2005; 52(12):3792-3800. [PubMed: 16320330]

4. Steen VD, Medsger TA. Changes in causes of death in systemic sclerosis, 1972-2002. Ann. Rheum. Dis. 2007; 66(7):940-944. [PubMed: 17329309]

5. Kawut SM, Taichman DB, Archer-Chicko CL, Palevsky HI, Kimmel SE. Hemodynamics and survival in patients with pulmonary arterial hypertension related to systemic sclerosis. Chest. 2003; 123(2):344-350. [PubMed: 12576350]

6. Fisher MR, Mathai SC, Champion HC, et al. Clinical differences between idiopathic and scleroderma-related pulmonary hypertension. Arthritis Rheum. 2006; 54(9):3043-3050. [PubMed: 16947776]

7. McLaughlin VV, Presberg KW, Doyle RL, et al. Prognosis of pulmonary arterial hypertension: ACCP evidence-based clinical practice guidelines. Chest. 2004; 126(Suppl. 1):78S-92S. [PubMed: 15249497]

8. Jimenez SA, Derk CT. Following the molecular pathways toward an understanding of the pathogenesis of systemic sclerosis. Ann. Intern. Med. 2004; 140(1):37-50. [PubMed: 14706971]

9. Tan FK. Systemic sclerosis: the susceptible host (genetics and environment). Rheum. Dis. Clin. North Am. 2003; 29(2):211-237. [PubMed: 12841292]

10. Arnett FC, Cho M, Chatterjee S, Aguilar MB, Reveille JD, Mayes MD. Familial occurrence frequencies and relative risks for systemic sclerosis (scleroderma) in three United States cohorts. Arthritis Rheum. 2001; 44(6):1359-1362. [PubMed: 11407695]

11. Feghali-Bostwick C, Medsger TA Jr, Wright TM. Analysis of systemic sclerosis in twins reveals low concordance for disease and high concordance for the presence of antinuclear antibodies. Arthritis Rheum. 2003; 48(7):1956-1963. [PubMed: 12847690]

12. Nietert PJ, Silver RM. Systemic sclerosis: environmental and occupational risk factors. Curr. Opin. Rheumatol. 2000; 12(6):520-526. [PubMed: 11092202]

13. Mayes MD. Scleroderma epidemiology. Rheum. Dis. Clin. North Am. 2003; 29(2):239-254. [PubMed: 12841293]

14. Mayes MD, Lacey JV Jr, Beebe-Dimmer J, et al. Prevalence, incidence, survival, and disease characteristics of systemic sclerosis in a large US population. Arthritis Rheum. 2003; 48(8):22462255. [PubMed: 12905479]

15. Allcock RJ, Forrest I, Corris PA, Crook PR, Griffiths ID. A study of the prevalence of systemic sclerosis in northeast England. Rheumatology (Oxford). 2004; 43(5):596-602. [PubMed: 14872101]

16. Tamaki T, Mori S, Takehara K. Epidemiological study of patients with systemic sclerosis in Tokyo. Arch. Dermatol. Res. 1991; 283(6):366-371. [PubMed: 1796818]

17. Steen VD, Oddis CV, Conte CG, Janoski J, Casterline GZ, Medsger TA Jr. Incidence of systemic sclerosis in Allegheny County, Pennsylvania. A twenty-year study of hospital-diagnosed cases, 1963-1982. Arthritis Rheum. 1997; 40(3):441-445. [PubMed: 9082931]

18. Le Guern V, Mahr A, Mouthon L, Jeanneret D, Carzon M, Guillevin L. Prevalence of systemic sclerosis in a French multi-ethnic county. Rheumatology (Oxford). 2004; 43(9):1129-1137. [PubMed: 15213329]

19. Chifflot H, Fautrel B, Sordet C, Chatelus E, Sibilia J. Incidence and prevalence of systemic sclerosis: a systematic literature review. Semin. Arthritis Rheum. 2008; 37(4):223-235. [PubMed: 17692364]

20. Laing TJ, Gillespie BW, Toth MB, et al. Racial differences in scleroderma among women in Michigan. Arthritis Rheum. 1997; 40(4):734-742. [PubMed: 9125258]

21. LeRoy EC, Black C, Fleischmajer R, et al. Scleroderma (systemic sclerosis), classification, subsets and pathogenesis. J. Rheumatol. 1988; 15(2):202-205. [PubMed: 3361530]

22. LeRoy EC, Medsger TA Jr. Criteria for the classification of early systemic sclerosis. J. Rheumatol. 2001; 28(7):1573-1576. [PubMed: 11469464]

23. Johnson DA, Drane WE, Curran J, et al. Pulmonary disease in progressive systemic sclerosis. A complication of gastroesophageal reflux and occult aspiration? Arch. Intern. Med. 1989; 149(3): 589-593. [PubMed: 2919934] 
24. Savarino E, Bazzica M, Zentilin P, et al. Gastroesophageal reflux and pulmonary fibrosis in scleroderma: a study using pH-impedance monitoring. Am. J. Respir. Crit. Care Med. 2009; 179(5):408-413. [PubMed: 19096004]

25. Roumm AD, Medsger TA Jr. Cancer and systemic sclerosis. An epidemiologic study. Arthritis Rheum. 1985; 28(12):1336-1340. [PubMed: 4084328]

26. Chatterjee S, Dombi GW, Severson RK, Mayes MD. Risk of malignancy in scleroderma: a population-based cohort study. Arthritis Rheum. 2005; 52(8):2415-2424. [PubMed: 16052585]

27. Olsen NJ, King LE Jr, Park JH. Muscle abnormalities in scleroderma. Rheum. Dis. Clin. North Am. 1996; 22(4):783-796. [PubMed: 8923596]

28. Thompson AE, Pope JE. A study of the frequency of pericardial and pleural effusions in scleroderma. Br. J. Rheumatol. 1998; 37(12):1320-1323. [PubMed: 9973157]

29. Vitali C, Viegi G, Tassoni S, et al. Lung function abnormalities in different connective tissue diseases. Clin. Rheumatol. 1986; 5(2):181-188. [PubMed: 3731715]

30. Lang B, Ortlieb H, Meske S, Hauke G, Peter HH. Progressive systemic sclerosis presenting with spontaneous pneumothorax. J. Rheumatol. 1989; 16(2):254-256. [PubMed: 2746577]

31. Varga J. Systemic sclerosis: an update. Bull. NYU Hosp. Jt Dis. 2008; 66(3):198-202. [PubMed: 18937632]

32. Morelli S, Barbieri C, Sgreccia A, et al. Relationship between cutaneous and pulmonary involvement in systemic sclerosis. J. Rheumatol. 1997; 24(1):81-85. [PubMed: 9002015]

33. Kane GC, Varga J, Conant EF, Spirn PW, Jimenez S, Fish JE. Lung involvement in systemic sclerosis (scleroderma), relation to classification based on extent of skin involvement or autoantibody status. Respir. Med. 1996; 90(4):223-230. [PubMed: 8736656]

34. McNearney TA, Reveille JD, Fischbach M, et al. Pulmonary involvement in systemic sclerosis: associations with genetic, serologic, sociodemographic, and behavioral factors. Arthritis Rheum. 2007; 57(2):318-326. [PubMed: 17330281]

35. Steen VD, Medsger TA Jr. Severe organ involvement in systemic sclerosis with diffuse scleroderma. Arthritis Rheum. 2000; 43(11):2437-2444. [PubMed: 11083266]

36. Battle RW, Davitt MA, Cooper SM, et al. Prevalence of pulmonary hypertension in limited and diffuse scleroderma. Chest. 1996; 110(6):1515-1519. [PubMed: 8989070]

37. Stupi AM, Steen VD, Owens GR, Barnes EL, Rodnan GP, Medsger TA Jr. Pulmonary hypertension in the CREST syndrome variant of systemic sclerosis. Arthritis Rheum. 1986; 29(4): 515-524. [PubMed: 3707629]

38. Humbert M, Sitbon O, Chaouat A, et al. Pulmonary arterial hypertension in France: results from a national registry. Am. J. Respir. Crit. Care Med. 2006; 173(9):1023-1030. [PubMed: 16456139]

39. Avouac J, Airo P, Meune C, et al. Prevalence of pulmonary hypertension in systemic sclerosis in European Caucasians and metaanalysis of 5 studies. J. Rheumatol. 2010; 37(11):2290-2298. [PubMed: 20810505]

40. Badesch DB, Raskob GE, Elliott CG, et al. Pulmonary arterial hypertension: baseline characteristics from the REVEAL Registry. Chest. 2010; 137(2):376-387. [PubMed: 19837821]

41. Overbeek MJ, Vonk MC, Boonstra A, et al. Pulmonary arterial hypertension in limited cutaneous systemic sclerosis: a distinctive vasculopathy. Eur. Respir. J. 2009; 34(2):371-379. [PubMed: 19282344]

42. Dorfmuller P, Humbert M, Perros F, et al. Fibrous remodeling of the pulmonary venous system in pulmonary arterial hypertension associated with connective tissue diseases. Hum. Pathol. 2007; 38(6):893-902. [PubMed: 17376507]

43. LeRoy EC. Systemic sclerosis. A vascular perspective. Rheum. Dis. Clin. North Am. 1996; 22(4): 675-694. [PubMed: 8923590]

44. Muller-Ladner U, Distler O, Ibba-Manneschi L, Neumann E, Gay S. Mechanisms of vascular damage in systemic sclerosis. Autoimmunity. 2009; 42(7):587-595. [PubMed: 19863377]

45. Sgonc R, Gruschwitz MS, Boeck G, Sepp N, Gruber J, Wick G. Endothelial cell apoptosis in systemic sclerosis is induced by antibody-dependent cell-mediated cytotoxicity via CD95. Arthritis Rheum. 2000; 43(11):2550-2562. [PubMed: 11083280] 
46. Cerinic MM, Valentini G, Sorano GG, et al. Blood coagulation, fibrinolysis, and markers of endothelial dysfunction in systemic sclerosis. Semin. Arthritis Rheum. 2003; 32(5):285-295. [PubMed: 12701039]

47. Denton CP, Bickerstaff MC, Shiwen X, et al. Serial circulating adhesion molecule levels reflect disease severity in systemic sclerosis. Br. J. Rheumatol. 1995; 34(11):1048-1054. [PubMed: 8542206]

48. Distler O, Del Rosso A, Giacomelli R, et al. Angiogenic and angiostatic factors in systemic sclerosis: increased levels of vascular endothelial growth factor are a feature of the earliest disease stages and are associated with the absence of fingertip ulcers. Arthritis Res. 2002; 4(6):R11. [PubMed: 12453314]

49. Choi JJ, Min DJ, Cho ML, et al. Elevated vascular endothelial growth factor in systemic sclerosis. J. Rheumatol. 2003; 30(7):1529-1533. [PubMed: 12858453]

50. Hebbar M, Peyrat JP, Hornez L, Hatron PY, Hachulla E, Devulder B. Increased concentrations of the circulating angiogenesis inhibitor endostatin in patients with systemic sclerosis. Arthritis Rheum. 2000; 43(4):889-893. [PubMed: 10765935]

51. Hummers LK, Hall A, Wigley FM, Simons M. Abnormalities in the regulators of angiogenesis in patients with scleroderma. J. Rheumatol. 2009; 36(3):576-582. [PubMed: 19228661]

52. Grigoryev DN, Mathai SC, Fisher MR, et al. Identification of candidate genes in sclerodermarelated pulmonary arterial hypertension. Transl. Res. 2008; 151(4):197-207. [PubMed: 18355767]

53. Okano Y, Steen VD, Medsger TA Jr. Autoantibody to U3 nucleolar ribonucleoprotein (fibrillarin) in patients with systemic sclerosis. Arthritis Rheum. 1992; 35(1):95-100. [PubMed: 1731817]

54. Rosen A, Casciola-Rosen L. Autoantigens in systemic autoimmunity: critical partner in pathogenesis. J. Intern. Med. 2009; 265(6):625-631. [PubMed: 19493056]

55. Tamby MC, Chanseaud Y, Humbert M, et al. Anti-endothelial cell antibodies in idiopathic and systemic sclerosis associated pulmonary arterial hypertension. Thorax. 2005; 60(9):765-772. [PubMed: 16135682]

56. Grigolo B, Mazzetti I, Meliconi R, et al. Anti-topoisomerase II a autoantibodies in systemic sclerosis-association with pulmonary hypertension and HLA-B35. Clin. Exp. Immunol. 2000; 121(3):539-543. [PubMed: 10971522]

57. Nicolls MR, Taraseviciene-Stewart L, Rai PR, Badesch DB, Voelkel NF. Autoimmunity and pulmonary hypertension: a perspective. Eur. Respir. J. 2005; 26(6):1110-1118. [PubMed: 16319344]

58. Mihai C, Tervaert JW. Anti-endothelial cell antibodies in systemic sclerosis. Ann. Rheum. Dis. 2010; 69(2):319-324. [PubMed: 20107031]

59. Tamby MC, Humbert M, Guilpain P, et al. Antibodies to fibroblasts in idiopathic and sclerodermaassociated pulmonary hypertension. Eur. Respir. J. 2006; 28(4):799-807. [PubMed: 16774952]

60. Tamby MC, Servettaz A, Tamas N, et al. IgG from patients with systemic sclerosis bind to DNA antitopoisomerase 1 in normal human fibroblasts extracts. Biologics. 2008; 2(3):583-591. [PubMed: 19707389]

61. Terrier B, Tamby MC, Camoin L, et al. Identification of target antigens of antifibroblast antibodies in pulmonary arterial hypertension. Am. J. Respir. Crit. Care Med. 2008; 177(10):1128-1134. [PubMed: 18276943]

62. Riemekasten G, Philippe A, Nather M, et al. Involvement of functional autoantibodies against vascular receptors in systemic sclerosis. Ann. Rheum. Dis. 2010; 70(3):530-536. [PubMed: 21081526]

63. Sanchez O, Sitbon O, Jais X, Simonneau G, Humbert M. Immunosuppressive therapy in connective tissue diseases-associated pulmonary arterial hypertension. Chest. 2006; 130(1):182189. [PubMed: 16840400]

64. Jais X, Launay D, Yaici A, et al. Immunosuppressive therapy in lupus- and mixed connective tissue disease-associated pulmonary arterial hypertension: a retrospective analysis of twenty-three cases. Arthritis Rheum. 2008; 58(2):521-531. [PubMed: 18240255]

65. Austin ED, Loyd JE. Genetics and mediators in pulmonary arterial hypertension. Clin. Chest Med. 2007; 28(1):43-57. VII-VIII. [PubMed: 17338927] 
66. Trembath RC, Thomson JR, Machado RD, et al. Clinical and molecular genetic features of pulmonary hypertension in patients with hereditary hemorrhagic telangiectasia. N. Engl. J. Med. 2001; 345(5):325-334. [PubMed: 11484689]

67. Girerd B, Montani D, Coulet F, et al. Clinical outcomes of pulmonary arterial hypertension in patients carrying an ACVRL1 (ALK1) mutation. Am. J. Respir. Crit. Care Med. 2010; 181(8): 851-861. [PubMed: 20056902]

68. Tew MB, Arnett FC, Reveille JD, Tan FK. Mutations of bone morphogenetic protein receptor type II are not found in patients with pulmonary hypertension and underlying connective tissue diseases. Arthritis Rheum. 2002; 46(10):2829-2830. [PubMed: 12384956]

69. Morse J, Barst R, Horn E, Cuervo N, Deng Z, Knowles J. Pulmonary hypertension in scleroderma spectrum of disease: lack of bone morphogenetic protein receptor 2 mutations. J. Rheumatol. 2002; 29(11):2379-2381. [PubMed: 12415595]

70. Wipff J, Kahan A, Hachulla E, et al. Association between an endoglin gene polymorphism and systemic sclerosis-related pulmonary arterial hypertension. Rheumatology (Oxford). 2007; 46(4): 622-625. [PubMed: 17166870]

71. Mattuzzi S, Barbi S, Carletto A, et al. Association of polymorphisms in the IL1B and IL2 genes with susceptibility and severity of systemic sclerosis. J. Rheumatol. 2007; 34(5):997-1004. [PubMed: 17444587]

72. Dieude P, Guedj M, Wipff J, et al. Association of the TNFAIP3 rs5029939 variant with systemic sclerosis in the European Caucasian population. Ann. Rheum. Dis. 2010; 69(11):1958-1964. [PubMed: 20511617]

73. Simonneau G, Barst RJ, Galie N, et al. Continuous subcutaneous infusion of treprostinil, a prostacyclin analogue, in patients with pulmonary arterial hypertension: a double-blind, randomized, placebo-controlled trial. Am. J. Respir. Crit. Care Med. 2002; 165(6):800-804. [PubMed: 11897647]

74. Girgis RE, Frost AE, Hill NS, et al. Selective endothelin A receptor antagonism with sitaxsentan for pulmonary arterial hypertension associated with connective tissue disease. Ann. Rheum. Dis. 2007; 66(11):1467-1472. [PubMed: 17472992]

75. MacDonald SL, Rubens MB, Hansell DM, et al. Nonspecific interstitial pneumonia and usual interstitial pneumonia: comparative appearances at and diagnostic accuracy of thin-section CT. Radiology. 2001; 221(3):600-605. [PubMed: 11719652]

76. Mathai SC, Hummers LK, Champion HC, et al. Survival in pulmonary hypertension associated with the scleroderma spectrum of diseases: impact of interstitial lung disease. Arthritis Rheum. 2009; 60(2):569-577. [PubMed: 19180517]

77. Condliffe R, Kiely DG, Peacock AJ, et al. Connective tissue disease-associated pulmonary arterial hypertension in the modern treatment era. Am. J. Respir. Crit. Care Med. 2009; 179(2):151-157. [PubMed: 18931333]

78. Campo A, Mathai SC, Le Pavec J, et al. Hemodynamic predictors of survival in sclerodermarelated pulmonary arterial hypertension. Am. J. Respir. Crit. Care Med. 2010; 182(2):252-260. [PubMed: 20339143]

79. Steen V, Medsger TA Jr. Predictors of isolated pulmonary hypertension in patients with systemic sclerosis and limited cutaneous involvement. Arthritis Rheum. 2003; 48(2):516-522. [PubMed: 12571862]

80. Schachna L, Wigley FM, Chang B, White B, Wise RA, Gelber AC. Age and risk of pulmonary arterial hypertension in scleroderma. Chest. 2003; 124(6):2098-2104. [PubMed: 14665486]

81. Chang B, Schachna L, White B, Wigley FM, Wise RA. Natural history of mild- moderate pulmonary hypertension and the risk factors for severe pulmonary hypertension in scleroderma. $\mathrm{J}$. Rheumatol. 2006; 33(2):269-274. [PubMed: 16465657]

82. Allanore Y, Borderie D, Avouac J, et al. High N-terminal pro-brain natriuretic peptide levels and low diffusing capacity for carbon monoxide as independent predictors of the occurrence of precapillary pulmonary arterial hypertension in patients with systemic sclerosis. Arthritis Rheum. 2008; 58(1):284-291. [PubMed: 18163505]

83. Steen VD. The many faces of scleroderma. Rheum. Dis. Clin. North Am. 2008; 34(1):1-15. V. [PubMed: 18329529] 
84. Campo A, Mathai SC, Le Pavec J, et al. Outcomes of hospitalization for right heart failure in pulmonary arterial hypertension. Eur. Respir. J. 2011 DOI: 10.1183/09031936.00148310. (Epub ahead of print).

85. Boueiz A, Mathai SC, Hummers LK, Hassoun PM. Cardiac complications of systemic sclerosis: recent progress in diagnosis. Curr. Opin. Rheumatol. 2010; 22(6):696-703. [PubMed: 20657283]

86. Mathai SC, Bueso M, Hummers LK, et al. Disproportionate elevation of N-terminal pro-brain natriuretic peptide in scleroderma-related pulmonary hypertension. Eur. Respir. J. 2010; 35(1):95104. [PubMed: 19643943]

87. Forfia PR, Mathai SC, Fisher MR, et al. Hyponatremia predicts right heart failure and poor survival in pulmonary arterial hypertension. Am. J. Respir. Crit. Care Med. 2008; 177(12):13641369. [PubMed: 18356560]

88. Chin KM, Kim NH, Rubin LJ. The right ventricle in pulmonary hypertension. Coron. Artery Dis. 2005; 16(1):13-18. [PubMed: 15654194]

89. Overbeek MJ, Lankhaar JW, Westerhof N, et al. Right ventricular contractility in systemic sclerosis-associated and idiopathic pulmonary arterial hypertension. Eur. Respir. J. 2008; 31(6): 1160-1166. [PubMed: 18216049]

90. Wigley FM, Lima JA, Mayes M, McLain D, Chapin JL, Ward-Able C. The prevalence of undiagnosed pulmonary arterial hypertension in subjects with connective tissue disease at the secondary health care level of community-based rheumatologists (the UNCOVER study). Arthritis Rheum. 2005; 52(7):2125-2132. [PubMed: 15986394]

91. Mangat P, Conron M, Gabbay E, Proudman SM. Scleroderma lung disease, variation in screening, diagnosis and treatment practices between rheumatologists and respiratory physicians. Intern. Med. J. 2010; 40(7):494-502. [PubMed: 19460060]

92. Huscher D, Pittrow D, Distler O, et al. Interactions between rheumatologists and cardio-/ pulmonologists in the assessment and use of outcome measures in pulmonary arterial hypertension related to systemic sclerosis. Clin. Exp. Rheumatol. 2010; 28(2 Suppl. 58):S47-S52. [PubMed: 20576214]

93. Miyamoto S, Nagaya N, Satoh T, et al. Clinical correlates and prognostic significance of sixminute walk test in patients with primary pulmonary hypertension. Comparison with cardiopulmonary exercise testing. Am. J. Respir. Crit. Care Med. 2000; 161(2 Pt 1):487-492. [PubMed: 10673190]

94. Avouac J, Kowal-Bielecka O, Pittrow D, et al. Validation of the 6 min walk test according to the OMERACT filter: a systematic literature review by the EPOSS-OMERACT group. Ann. Rheum. Dis. 2010; 69(7):1360-1363. [PubMed: 20472586]

95. Gilbert C, Brown MC, Cappelleri JC, Carlsson M, McKenna SP. Estimating a minimally important difference in pulmonary arterial hypertension following treatment with sildenafil. Chest. 2009; 135(1):137-142. [PubMed: 18812447]

96. Galie N, Ghofrani HA, Torbicki A, et al. Sildenafil citrate therapy for pulmonary arterial hypertension. N. Engl. J. Med. 2005; 353(20):2148-2157. [PubMed: 16291984]

97. Garin MC, Highland KB, Silver RM, Strange C. Limitations to the 6-minute walk test in interstitial lung disease and pulmonary hypertension in scleroderma. J. Rheumatol. 2009; 36(2):330-336. [PubMed: 19208563]

98. Sitbon O, Humbert M, Nunes H, et al. Long-term intravenous epoprostenol infusion in primary pulmonary hypertension: prognostic factors and survival. J. Am. Coll. Cardiol. 2002; 40(4):780 788. [PubMed: 12204511]

99. Provencher S, Sitbon O, Humbert M, Cabrol S, Jais X, Simonneau G. Long-term outcome with first-line bosentan therapy in idiopathic pulmonary arterial hypertension. Eur. Heart J. 2006; 27(5): 589-595. [PubMed: 16431875]

100. Distler O, Behrens F, Pittrow D, et al. Defining appropriate outcome measures in pulmonary arterial hypertension related to systemic sclerosis: a Delphi consensus study with cluster analysis. Arthritis Rheum. 2008; 59(6):867-875. [PubMed: 18512721]

101. Nagaya N, Uematsu M, Satoh T, et al. Serum uric acid levels correlate with the severity and the mortality of primary pulmonary hypertension. Am. J. Respir. Crit. Care Med. 1999; 160(2):487492. [PubMed: 10430718] 
102. Fijalkowska A, Kurzyna M, Torbicki A, et al. Serum N-terminal brain natriuretic peptide as a prognostic parameter in patients with pulmonary hypertension. Chest. 2006; 129(5):1313-1321. [PubMed: 16685024]

103. Williams MH, Handler CE, Akram R, et al. Role of N-terminal brain natriuretic peptide (NTproBNP) in scleroderma-associated pulmonary arterial hypertension. Eur. Heart J. 2006; 27(12):1485-1494. [PubMed: 16682379]

104. Forfia PR, Fisher MR, Mathai SC, et al. Tricuspid annular displacement predicts survival in pulmonary hypertension. Am. J. Respir. Crit. Care Med. 2006; 174(9):1034-1041. [PubMed: 16888289]

105. Giaid A, Saleh D. Reduced expression of endothelial nitric oxide synthase in the lungs of patients with pulmonary hypertension. N. Engl. J. Med. 1995; 333(4):214-221. [PubMed: 7540722]

106. Giaid A, Yanagisawa M, Langleben D, et al. Expression of endothelin-1 in the lungs of patients with pulmonary hypertension. N. Engl. J. Med. 1993; 328(24):1732-1739. [PubMed: 8497283]

107. Tuder RM, Cool CD, Geraci MW, et al. Prostacyclin synthase expression is decreased in lungs from patients with severe pulmonary hypertension. Am. J. Respir. Crit. Care Med. 1999; 159(6): 1925-1932. [PubMed: 10351941]

108. Adnot S. Lessons learned from cancer may help in the treatment of pulmonary hypertension. J. Clin. Invest. 2005; 115(6):1461-1463. [PubMed: 15931382]

109. Sitbon O, Humbert M, Jais X, et al. Long-term response to calcium channel blockers in idiopathic pulmonary arterial hypertension. Circulation. 2005; 111(23):3105-3111. [PubMed: 15939821]

110. Pietra GG, Edwards WD, Kay JM, et al. Histopathology of primary pulmonary hypertension. A qualitative and quantitative study of pulmonary blood vessels from 58 patients in the National Heart, Lung, and Blood Institute, Primary Pulmonary Hypertension Registry. Circulation. 1989; 80(5):1198-1206. [PubMed: 2805258]

111. Johnson SR, Mehta S, Granton JT. Anticoagulation in pulmonary arterial hypertension: a qualitative systematic review. Eur. Respir. J. 2006; 28(5):999-1004. [PubMed: 17074918]

112. Barst RJ, Rubin LJ, Long WA, et al. A comparison of continuous intravenous epoprostenol (prostacyclin) with conventional therapy for primary pulmonary hypertension. The Primary Pulmonary Hypertension Study Group. N. Engl. J. Med. 1996; 334(5):296-302. [PubMed: 8532025]

113. Rubin LJ, Mendoza J, Hood M, et al. Treatment of primary pulmonary hypertension with continuous intravenous prostacyclin (epoprostenol). Results of a randomized trial. Ann. Intern. Med. 1990; 112(7):485-491. [PubMed: 2107780]

114. Badesch DB, Tapson VF, McGoon MD, et al. Continuous intravenous epoprostenol for pulmonary hypertension due to the scleroderma spectrum of disease. A randomized, controlled trial. Ann. Intern. Med. 2000; 132(6):425-434. [PubMed: 10733441]

115. Oudiz RJ, Schilz RJ, Barst RJ, et al. Treprostinil, a prostacyclin analogue, in pulmonary arterial hypertension associated with connective tissue disease. Chest. 2004; 126(2):420-427. [PubMed: 15302727]

116. Oudiz RJ, Farber HW. Dosing considerations in the use of intravenous prostanoids in pulmonary arterial hypertension: an experience-based review. Am. Heart J. 2009; 157(4):625-635. [PubMed: 19332188]

117. McLaughlin VV, Benza RL, Rubin LJ, et al. Addition of inhaled treprostinil to oral therapy for pulmonary arterial hypertension: a randomized controlled clinical trial. J. Am. Coll. Cardiol. 2010; 55(18):1915-1922. [PubMed: 20430262]

118. Rubin LJ, Badesch DB, Barst RJ, et al. Bosentan therapy for pulmonary arterial hypertension. N. Engl. J. Med. 2002; 346(12):896-903. [PubMed: 11907289]

119. Denton CP, Pope JE, Peter HH, et al. Long-term effects of bosentan on quality of life, survival, safety and tolerability in pulmonary arterial hypertension related to connective tissue diseases. Ann. Rheum. Dis. 2008; 67(9):1222-1228. [PubMed: 18055477]

120. Girgis RE, Mathai SC, Krishnan JA, Wigley FM, Hassoun PM. Long-term outcome of bosentan treatment in idiopathic pulmonary arterial hypertension and pulmonary arterial hypertension associated with the scleroderma spectrum of diseases. J. Heart Lung Transplant. 2005; 24(10): 1626-1631. [PubMed: 16210140] 
121. Barst RJ, Langleben D, Frost A, et al. Sitaxsentan therapy for pulmonary arterial hypertension. Am. J. Respir. Crit. Care Med. 2004; 169(4):441-447. [PubMed: 14630619]

122. Galie N, Badesch D, Oudiz R, et al. Ambrisentan therapy for pulmonary arterial hypertension. J. Am. Coll. Cardiol. 2005; 46(3):529-535. [PubMed: 16053970]

123. Galie N, Brundage BH, Ghofrani HA, et al. Tadalafil therapy for pulmonary arterial hypertension. Circulation. 2009; 119(22):2894-2903. [PubMed: 19470885]

124. Avouac J, Wipff J, Kahan A, Allanore Y. Effects of oral treatments on exercise capacity in systemic sclerosis related pulmonary arterial hypertension: a meta-analysis of randomised controlled trials. Ann. Rheum. Dis. 2008; 67(6):808-814. [PubMed: 17901091]

125. Simonneau G, Rubin LJ, Galie N, et al. Addition of sildenafil to long-term intravenous epoprostenol therapy in patients with pulmonary arterial hypertension: a randomized trial. Ann. Intern. Med. 2008; 149(8):521-530. [PubMed: 18936500]

126. Mathai SC, Girgis RE, Fisher MR, et al. Addition of sildenafil to bosentan monotherapy in pulmonary arterial hypertension. Eur. Respir. J. 2007; 29(3):469-475. [PubMed: 17079256]

127. Paul GA, Gibbs JS, Boobis AR, Abbas A, Wilkins MR. Bosentan decreases the plasma concentration of sildenafil when coprescribed in pulmonary hypertension. Br. J. Clin. Pharmacol. 2005; 60(1):107-112. [PubMed: 15963102]

128. Ghofrani HA, Seeger W, Grimminger F. Imatinib for the treatment of pulmonary arterial hypertension. N. Engl. J. Med. 2005; 353(13):1412-1413. [PubMed: 16192491]

129. Patterson KC, Weissmann A, Ahmadi T, Farber HW. Imatinib mesylate in the treatment of refractory idiopathic pulmonary arterial hypertension. Ann. Intern. Med. 2006; 145(2):152-153. [PubMed: 16847299]

130. Souza R, Sitbon O, Parent F, Simonneau G, Humbert M. Long term imatinib treatment in pulmonary arterial hypertension. Thorax. 2006; 61(8):736. [PubMed: 16877696]

131. Overbeek MJ, van Nieuw Amerongen GP, Boonstra A, Smit EF, Vonk-Noordegraaf A. Possible role of imatinib in clinical pulmonary veno-occlusive disease. Eur. Respir. J. 2008; 32(1):232235. [PubMed: 18591341]

132. ten Freyhaus H, Dumitrescu D, Bovenschulte H, Erdmann E, Rosenkranz S. Significant improvement of right ventricular function by imatinib mesylate in scleroderma-associated pulmonary arterial hypertension. Clin. Res. Cardiol. 2009; 98(4):265-267. [PubMed: 19219392]

133. Ghofrani HA, Morrell NW, Hoeper MM, et al. Imatinib in pulmonary arterial hypertension patients with inadequate response to established therapy. Am. J. Respir. Crit. Care Med. 2010; 182(9):1171-1177. [PubMed: 20581169]

134. Reich N, Maurer B, Akhmetshina A, et al. The transcription factor Fra-2 regulates the production of extracellular matrix in systemic sclerosis. Arthritis Rheum. 2010; 62(1):280-290. [PubMed: 20039427]

135. Maurer B, Busch N, Jungel A, et al. Transcription factor fos-related antigen-2 induces progressive peripheral vasculopathy in mice closely resembling human systemic sclerosis. Circulation. 2009; 120(23):2367-2376. [PubMed: 19933934]

136. Schachna L, Medsger TA Jr, Dauber JH, et al. Lung transplantation in scleroderma compared with idiopathic pulmonary fibrosis and idiopathic pulmonary arterial hypertension. Arthritis Rheum. 2006; 54(12):3954-3961. [PubMed: 17133609]

137. Hassoun PM. Therapies for scleroderma-related pulmonary arterial hypertension. Expert Rev. Respir. Med. 2009; 3(2):187-196. [PubMed: 19885388]

138. Mathai SC, Hassoun PM. Therapy for pulmonary arterial hypertension associated with systemic sclerosis. Curr. Opin. Rheumatol. 2009; 21:642-648. [PubMed: 19667994] 


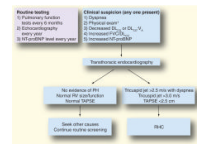

Figure 1. Proposed diagnostic algorithm for pulmonary arterial hypertension in patients with systemic sclerosis employed by the Johns Hopkins Pulmonary Hypertension Program $\dagger$ Elevated jugular venous pressure, increased second heart sound, RV tap or heave, peripheral edema.

$\mathrm{DL}_{\mathrm{CO}}$ : Diffusing capacity for carbon monoxide; FVC: Forced vital capacity; NT-proBNP: N-terminal pro-brain natriuretic peptide; PH: Pulmonary hypertension; RHC: Right heart catheterization; RV: Right ventricle; TAPSE: Tricuspid annular plane systolic excursion; $\mathrm{V}_{\mathrm{A}}$ : Alveolar volume.

Adapted from [137]. 


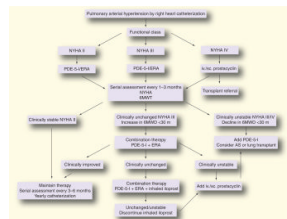

Figure 2. Clinical treatment algorithm for pulmonary arterial hypertension associated with systemic sclerosis employed by the Johns Hopkins Pulmonary Hypertension Program 6MWD: 6-min walk distance; 6MWT: 6-min walk test; AS: Atrial septostomy; ERA: Endothelin receptor antagonist; iv.: Intravenous; NYHA: New York Heart Association; PDE-5-I: Phosphodiesterase type-5 inhibitor; sc.: Subcutaneous.

Reproduced from [138]. 